\title{
Solid Particle Erosion of Duplex Stainless Steel with and Without Nichrome Coating
}

\author{
Roshan Kuruvila, S. Thirumalai Kumaran, M. Adam Khan
}

\begin{abstract}
Premature failure of material is one of the major issues in most of the engineering applications. The material degradation may be due to many reasons. Erosion is one of the major contributors to this issue. In order to extend the life of the material the erosion has to be minimized. Atmospheric Plasma Coating is one of the effective methods of coating to minimize erosion. Studies have established that coating Nichrome can reduce the rate of erosion. In the present study erosion rate was calculated by varying the parameters like angle of impact, velocity and mass flow rate with the help of air-jet erosion test equipment. The erosion rates of coated and uncoated DSS were analyzed. Erosion rate was calculated on the weight loss. On analysis of the data it was established that coatings can reduce the rate of erosion.
\end{abstract}

Keywords : coatings, duplex steel, erosion, nichrome.

\section{INTRODUCTION}

The erosion caused by the solid particles is one of the major concerns for the industries. [1] Over the year's researchers were trying to establish a solid model for the erosion but the complexity of the problem makes it more difficult to have a common model. Researches on erosion have found that coatings can considerably reduce the rate of erosion. [2, 3]. Thermal spray coating practices such as Atmospheric Plasma Spraying (APS) processes are usually used in coating components because it is the most flexible or adaptable and enables deposition of many ceramic materials and related mixture [4]. The studies conducted on Nichrome concluded that it possesses high wear resistance [5]. The objective of this paper is to have a comparison of erosion rates of Nichrome coated DSS and the uncoated DSS. The experiments were completed at normal standard conditions by varying the parameters in different combinations using an air-jet erosion test rig.

\section{EXPERIMENTAL SETUP}

\section{A. Submission of the paper}

Duplex steel of $25 \mathrm{~mm}$ x $25 \mathrm{~mm}$ x $5 \mathrm{~mm}$ size was selected

Revised Manuscript Received on December 30, 2019.

* Correspondence Author

Roshan Kuruvila, Department of Automobile Engineering, Kalasalingam Academy of Research and Education, Krishnankoil-626126, India. Email: roskur69@gmail.com

S. Thirumalai Kumaran*, Faculty of Mechanical Engineering, Kalasalingam Academy of Research and Education, Krishnankoil-626126, India. Email: thirumalaikumaran@yahoo.com

M. Adam Khan, Department of Mechanical and Industrial Engineering Technology, University of Johannesburg, Johannesburg, South Africa. Email: adamkhanm@gmail.com one set of specimens were coated with Nichrome and other not, both the surfaces were not polished to maintain surface roughness. Erosion experiments were performed by using the test rig of Air Jet Erosion, at the Kalasalingam Academy for Higher Education, Tamil Nadu, India. The erosion tests were accomplished at standard conditions. The abrasive parameters such as feed rate, pressure and the impact velocities are controlled by the pressure of the compressed air [6]. The impact over the specimen at various angles is done by using adjustable specimen holders. Aluminum oxide with a dimension of 50 microns with chemical composition of $95 \%$, $\mathrm{Al}_{2} \mathrm{O}_{3}$ was used as the abrasive particle. The specimens were washed and, weighed by an accurate weighing machine with an accuracy of $0.01 \mathrm{mg}$. This method was repeated for attaining the rate of erosion rate at various combinations as per ASTM standard G76-95.

\section{RESULTS AND DISCUSSION}

The rate of erosion of Duplex stainless steel specimens at diverse combinations of parameters such as impact angle, flow velocity and mass flow rate for coated and uncoated specimens are shown in Figure 1-3. The erosion rate is higher for higher angle of impact and low at lower angle of impact. Similarly, when flow velocity is increasing the erosion rate is also increasing.

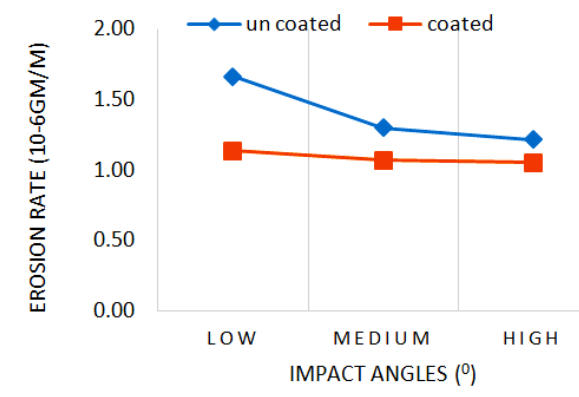

Fig. 1. Erosion rate at different impact angles.

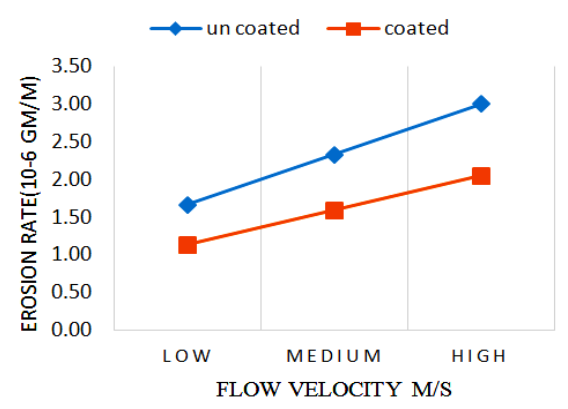

Fig. 2. Erosion rate at different flow velocities. 


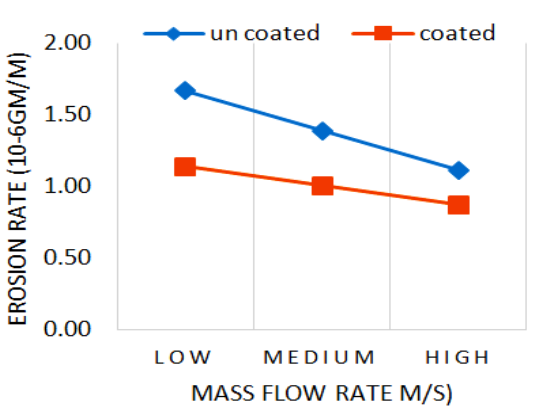

Fig. 3. Erosion rate at different flow rate

Generally, erosion rate is inversely proportional to the mass flow rate. The influence of all the parameters is analyzed by the loss of material calculated by taking the weight loss using and accurate weighing machine. The Increase in the loss of material at higher particle speeds are due to that the abrasive particles is achieving greater kinetic energy [7, 8]. As the angle of impact is increasing the rate of erosion reduces this due to the increase in the contact area. The increase in the contact results in the collision between the reflecting particles and the incoming particles and thereby reducing the energy of impact $[9,10]$. The relationship between the mass flow rate and erosions shows that they are inversely proportional. this due to a large number of abrasive particles coming out of the nozzle but most of them are not striking the surface due to many reasons such scattering of abrasive particle etc. on the analysis of the above data's it is clear that atmospheric plasma sprayed coatings on the duplex steel has been able to reduce the rate of erosion considerably under all the situations. The experimental results confirm that the coated specimen offered more resistance to erosion than the uncoated specimen under same conditions.

\section{CONCLUSION}

The experiment on solid particle erosion on duplex stainless steel with and without coating nichrome was performed on high pressure air jet and the following conclusions were made.

- The significance of all the parameters such as impact angle, flow velocity and mass flow rate was clearly established to control the rate of erosion.

- The erosion rate increases with the increase in flow velocity and decrease with the increase in impact angle and mass flow rate.

- Coated Duplex steel showed good resistance erosion when compared with uncoated Duplex steel under all conditions.

- It can be concluded that any composite material can be effectively coated over the surface over the improved performance in all tribological applications.

\section{REFERENCES}

1. Alan V. Levy and Pauline Chik, "The Effects of erodent composition and shape on the erosion of steel," Wear, vol.89, 1983, pp. 151-162.

2. Ronghua Wei, Edward Langa, Christopher Rincon and James H.Arps, "Deposition of thick nitrides and carbonitrides for sand erosion protection," Surface and Coating Technology, vol. 201, 2006, pp. 4453-4459.

3. S.B. Mishra, S. Prakash and K. Chandra, "Studies on erosion behavior of plasma sprayed coatings on a Ni-based super alloy," Wear, vol. 260, 2006, pp. 422-432.
4. G. Di Girolamo, A. Brentari, C. Blasi and E. Serra, "Microstructure and mechanical properties of plasma sprayed alumina-based coatings," Ceramics International, vol. 40, 2014, pp. 12861-12867.

5. D. Sudhakara, D. Jeyasimman and M. Duraiselvam, "Dry sliding wear behavior of $\mathrm{Cr} 3 \mathrm{C} 2-\mathrm{NiCr}$ coating on austenitic stainless steel," International Journal of Core Engineering \& Management, vol. 1, 2015, pp. 215-225.

6. Mayank Patela, Darshan Patela, S. Sekar, P. B. Tailora and P. V. Ramanaa, "Study of solid particle erosion behaviour of SS 304 at room temperature," Procedia Technology, vol. 23, 2016, pp. 288-295.

7. S. Söderberg, S. Hogmark and H. Swahn, "Mechanisms of material removal during erosion of a stainless steel," ASLE Transactions, vol. 26, 1983, pp. 161-172.

8. I. M. Hutchings, R. E. Winter and John Edwin Field, "Solid particle erosion of metals: the removal of surface material by spherical projectiles," Proceedings of the Royal Society A, vol. 348, 1976, pp. 379-392.

9. M. Divakar, V. K. Agarwal and S. N. Singh, "Effect of the material surface hardness on the erosion of AISI316,"Wear, vol. 259, 2005, pp. 110-117.

10. J. R. Laguna-Camacho, L. A. Cruz-Mendoza, J. C. Anzelmetti-Zaragoza, A. Marquina-Chávez, M. Vite-Torres and J. Martínez-Trinidad, "Solid particle erosion on coatings employed to protect die casting molds," Progress in Organic Coatings, vol. 74, 2012, pp. 750-757.

\section{AUTHORS PROFILE}

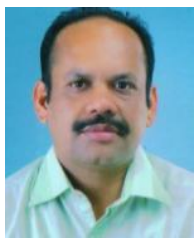

Roshan Kuruvila is a Research Scholar at Department of Automobile Engineering in Kalasalingam Academy of Research and Education, Krishnankoil. Currently he is working as Assistant Professor in Amal Jyothi College of Engineering, Kerala.

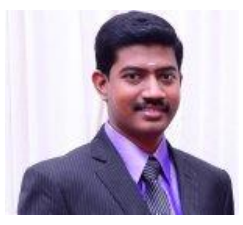

S. Thirumalai Kumaran completed his Ph.D. degree in Mechanical Engineering from Kalasalingam Academy of Research and Education (KARE), India, in 2015. After completing Ph.D., he worked as an Assistant Professor at School of Mechanical Engineering, Yeungnam University, South Korea for a period of one year. He is currently an Associate Professor at School of Automotive and Mechanical Engineering, KARE.

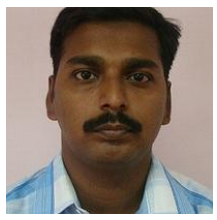

M. Adam Khan completed his Ph.D. degree in Mechanical Engineering from National Institute of Technology, Trichy. Currently he is working as a post-doctoral fellow in University of Johannesburg, South Africa. His area of interest includes coating, high temperature corrosion and machining of composites. 